Pacific Journal of Mathematics

FIXED-POINT THEOREMS FOR FAMILIES OF CONTRACTION 


\title{
FIXED-POINT THEOREMS FOR FAMILIES OF CONTRACTION MAPPINGS
}

\author{
L. P. Belluce and W. A. KirK
}

Let $X$ be a nonempty, bounded, closed and convex subset of a Banach space $B$. A mapping $f: X \rightarrow X$ is called a contraction mapping if $\|f(x)-f(y)\| \leqq\|x-y\|$ for all $x, y \in X$. Let $\mathfrak{F}$ be a nonempty commutative family of contraction mappings of $X$ into itself. The following results are obtained.

(i) Suppose there is a compact subset $M$ of $X$ and a mapping $f_{1} \in \widetilde{f}$ such that for each $x \in X$ the closure of the set $\left\{f_{1}^{n}(x): n=1,2, \cdots\right\}$ contains a point of $M$ (where $f_{1}^{n}$ denotes the $n^{\text {th }}$ iterate, under composition, of $f_{1}$ ). Then there is a point $x \in M$ such that $f(x)=x$ for each $f \in \widetilde{\mho}$.

(ii) If $X$ is weakly compact and the norm of $B$ strictly convex, and if for each $f \in \widetilde{\mho}$ the $f$-closure of $X$ is nonempty, then there is a point $x \in X$ which is fixed under each $f \in \widetilde{F}$. A third theorem, for finite families, is given where the hypotheses are in terms of weak compactness and a concept of Brodskii and Milman called normal structure.

Fixed-point theorems for families of continuous linear (or affine) transformations have been obtained by Kakutani [6], Markov [8], Day [2], and others. Recently De Marr [3] proved the following fixed-point theorem: If $X$ is a nonempty, compact, convex subset of a Banach space $B$ and if $\widetilde{F}$ is a nonempty family of commuting contraction mappings of $X$ into itself, then the family $\mathfrak{F}$ has a common fixed point in $X$. In Theorem 1 of this paper hypotheses of a type considered by Göhde in [5] are used to obtain a generalization of De Marr's result.

Throughout this paper we shall denote the diameter of a subset $A \subseteq B$ by $\delta(A)$, i.e.,

$$
\delta(A)=\sup \{\|x-y\|: x, y \in A\} .
$$

THEOREM 1. Let $X$ be a nonempty, bounded, closed, convex subset of a Banach space $B$; let $M$ be a compact subset of $X$. Let $\mathfrak{F}$ be a nonempty commutative family of contraction mappings of $X$ into itself with the property that for some $f_{1} \in \mathfrak{F}$ and for each $x \in X$ the closure of the set $\left\{f_{1}^{n}(x): n=1,2, \cdots\right\}$ contains a point of $M$. Then there is a point $x \in M$ such that $f(x)=x$ for each $f \in \mathfrak{F}$.

Proof. Let $K$ be a nonempty closed convex subset of $X$ such that $f(K) \subseteq K$ for each $f \in \widetilde{F}$. Select a point $x \in K$. Since $f(K) \subseteq K$, we have $\left\{f_{1}^{n}(x)\right\} \subseteq K$. Hence it follows that 


$$
K \cap M \supseteqq \overline{\left\{f_{1}^{n}(x)\right\}} \cap M \neq \varnothing .
$$

Thus we may apply Zorn's Lemma to obtain subset $X^{*}$ of $X$ which is minimal with respect to being nonempty, closed, convex and mapped into itself by each $f \in \widetilde{F}$. Let $M^{*}=X^{*} \cap M$; from the above remarks we know $M^{*} \neq \varnothing$. By a theorem of Göhde [5, p. 54], $f_{1}$ has a nonempty fixed-point set $H$ in $M^{*}$. Since $H$ is the set of all fixed-points of $f_{1}$, it is closed. Let $x \in H$ and $y=f(x)$. Then we have

$$
f_{1}(y)=f_{1}[f(x)]=f\left[f_{1}(x)\right]=f(x)=y
$$

since the set $\mathfrak{F}$ is commutative and $x$ is a fixed-point of $f_{1}$. Hence $y \in H$ and $f(H) \subseteq H$ for each $f \in \mathfrak{F}$. We are therefore able to find a subset $H^{*}$ of $H$ which is minimal with respect to being nonempty, closed and mapped into itself by each $f \in \mathfrak{F}$.

Let $g \in \widetilde{F}$. Since $H^{*}$ is compact and $g$ continuous, $g\left(H^{*}\right)$ is closed. For each $f \in \mathfrak{F}, f\left[g\left(H^{*}\right)\right]=g\left[f\left(H^{*}\right)\right] \subseteq g\left(H^{*}\right)$. Thus if $g\left(H^{*}\right)$ is a proper subset of $H^{*}$ for some $g \in \mathfrak{F}$, then the minimality of $H^{*}$ is contradicted. Hence $H^{*}$ is mapped onto itself by each member of $\mathfrak{F}$. Let $W$ denote the convex closure of $H^{*}$. Since $H^{*}$ is compact, so is $W$. If $\delta(W)>0$ it follows (see De Marr [3; Lemma 1]) that there is a point $x \in W$ such that

$$
\sup \{\|x-z\|: z \in W\}=r<\delta(W) .
$$

We shall show that this leads to a contradiction and thereby conclude that $\delta(W)=0$. Thus, let

$$
\begin{aligned}
& C_{1}=\left\{w \in W:\|w-z\| \leqq r \text { for all } z \in H^{*}\right\}, \\
& C_{2}=\left\{w \in X^{*}:\|w-z\| \leqq r \text { for all } z \in H^{*}\right\} .
\end{aligned}
$$

Clearly $C_{1}=C_{2} \cap W$. Since $H^{*}$ is mapped onto itself by each member of $\mathfrak{F}$, it is easily seen $f\left(C_{2}\right) \subseteq C_{2}$ for each $f \in \mathfrak{F}$. Since $C_{2}$ is a nonempty closed convex subset of $X^{*}$, the minimality of $X^{*}$ implies $C_{2}=X^{*}$. Therefore $C_{1}=W$. But since $\delta\left(H^{*}\right)=\delta(W)$ there are points $x, y \in H^{*}$ such that $\|x-y\|>r$. However $H^{*} \subseteq W=C_{1}$ implies $\|x-y\| \leqq r$. This contradiction shows $\delta(W)=0$ and $H^{*}$ (hence $X^{*}$ ) consists of a single point which must be fixed under each mapping in $\mathfrak{F}$.

That De Marr's theorem follows from the above is evident. The following definition may be found in [4].

Definition. Let $X$ be a nonempty subset of a Banach space $B$ and let $f: X \rightarrow X$ be a contraction. The f-closure of $X$, denoted by $X^{\jmath}$, is the set of points $y \in B$ such that for some $x \in X$ a subsequence of $\left\{f^{n}(x)\right\}$ converges to $y$. 
THEOREM 2. Suppose $X$ is a nonempty, weakly compact, convex subset of a Banach space $B$ whose norm is strictly convex. Suppose $\mathfrak{F}$ is a nonempty commutative family of contraction mappings of $X$ into itself such that for each $f \in \mathfrak{F}, X^{\jmath} \neq \varnothing$. Then there is an $x \in$ $X$ such that $f(x)=x$ for each $f \in \mathfrak{F}$.

Proof. It follows from a result of Edelstein [4; p. 441, II] that each member of $\mathfrak{F}$ has a nonempty fixed point set in $X$. (Although the mappings in [4] are defined on the entire Banach space the same results can be obtained when the domain is restricted as in this theorem.) Because the norm of $B$ is strictly convex, and the mappings considered are contractions, it is easily seen that each of these fixedpoint sets is convex (and closed). As closed convex subsets of the weakly compact set $X$, they are themselves weakly compact. Thus we need only show that these fixed-point sets have the finite intersection property to conclude that there is a point common to all of them.

We make the inductive assumption that each $n$ members of $\mathfrak{F}$ have a common fixed-point in $X$. Let $f_{1}, f_{2}, \cdots, f_{n+1} \in \mathfrak{F}$. Let $M$ be the set of common fixed points of $f_{1}, \cdots, f_{n}$. Then $M$ is weakly compact and if $y \in M, f_{i}\left[f_{n+1}(y)\right]=f_{n+1}\left[f_{i}(y)\right]=f_{n+1}(y)$ for each $i=$ $1,2, \cdots, n$. Hence $f_{n+1}(y) \in M$ and $f_{n+1}(M) \cong M$. Let $y$ be a point of $X$ fixed under $f_{n+1}$. The strict convexity of the norm together with the weak compactness of $M$ enable us to obtain a unique point $x \in M$ nearest to $y$. Since $f_{n+1}$ is a contraction it then follows that $f_{n+1}(x)=$ $x$. Thus $x$ is a common fixed point of $f_{1}, \cdots, f_{n+1}$. The proof is now complete.

The concept defined below was first introduced by Brodskii and Milman in [1].

Definition. A bounded convex set $K$ in a Banach space $B$ is said to have normal structure if for each convex subset $H$ of $K$ which contains more than one point there is a point $x \in H$ which is not a diametral point of $H$, (i.e. $\sup \{\|x-y\|: y \in H\}<\delta(H)$ ).

By replacing strict convexity of the norm by normal structure and removing the requirement that $X^{\jmath} \neq \varnothing$ we obtain the following theorem for weakly compact sets $X$. Unfortunately, we have only been able to establish this theorem for finite families (or, of course, finitely generated families) of commuting contractions.

THEOREM 3. Suppose $X$ is a nonempty, weakly compact, convex subset of a Banach space $B$ and suppose that $X$ has normal structure. If $\mathfrak{F}$ is a finite family of commuting contraction mappings of $X$ into itself then there is an $x \in X$ such that $f(x)=x$ for each $f \in \mathfrak{F}$. 
That this theorem holds if $\mathfrak{F}$ consists of a single mapping follows from [7]. However, we take this opportunity to establish a slightly more general result which also serves our purpose.

Theorem 4. Let $X$ be a bounded, closed, convex subset of a Banach space $B$ and suppose that $X$ has normal structure. Let $M$ be a weakly compact subset of $X$. Assume $f$ is a contraction mapping of $X$ into itself with the property that for each $x \in X$, the closure of $\left\{f^{n}(x): n=1,2, \cdots\right\}$ contains a point of $M$. Then there is an $x \in M$ such that $f(x)=x$.

Proof of Theorem 4. Since closed and convex subsets of $X$ are weakly closed and since $M$ is weakly compact, Zorn's lemma gives us a subset $X^{*}$ of $X$ which is minimal with respect to being nonempty, closed, convex, mapped into itself by $f$, and having points in common with $M$. By normal structure, if $\delta\left(X^{*}\right)>0$ then there is a point $x \in X^{*}$ such that

$$
\sup \left\{\|x-z\|: z \in X^{*}\right\}=r<\delta\left(X^{*}\right) .
$$

Assume, then, that $\delta\left(X^{*}\right)>0$. Let

$$
C=\left\{z \in X^{*}:\|z-y\| \leqq r \text { for each } y \in X^{*}\right\} .
$$

Then $C$ is nonempty. Let $K$ denote the convex closure of $f\left(X^{*}\right)$. Since $K \subseteq X^{*}$, then $f(K) \subseteq f\left(X^{*}\right)$. The closure of $f\left(X^{*}\right)$ is contained in $K$ and the hypotheses on $f$ imply that this set intersects $M$. Hence $M \cap K \neq \varnothing$. By the minimality of $X^{*}$ we conclude that $K=$ $X^{*}$. Let

$$
C_{1}=\left\{z \in X^{*}:\|z-y\| \leqq r \text { for all } y \in f\left(X^{*}\right)\right\} .
$$

Clearly $C \subseteq C_{1}$. But if $z \in C_{1}$ then any spherical ball of radius $r$ centered at $z$ must contain $f\left(X^{*}\right)$, and hence it must contain $K=X^{*}$. Consequently $C_{1} \subseteq C$, and therefore $C_{1}=C$.

Let $z \in C$ and $y \in f\left(X^{*}\right)$. Then $y=f(x)$ for some $x \in X^{*}$ and we have

$$
\|f(z)-y\|=\|f(z)-f(x)\| \leqq\|z-x\| \leqq r .
$$

Therefore $f(C) \subseteq C$. This implies, by the minimality of $X^{*}$, that $C=X^{*}$. But $\delta(C) \leqq r<\delta\left(X^{*}\right)$. This contradiction shows that $\delta\left(X^{*}\right)=0$. Therefore $X$ consists of a single point which must be fixed under $f$.

We now return to Theorem 3 .

Proof of Theorem 3. Suppose $\mathfrak{F}=\left\{f_{1}, f_{2}, \cdots, f_{n}\right\}$. Since $X$ is 
weakly compact we can find a subset $X^{*}$ of $X$ minimal with respect to being nonempty, closed, convex and mapped into itself by each element of $\Im$. Let $W$ denote the set of points of $X^{*}$ fixed under $f_{1} f_{2} \cdots f_{n}$. By Theorem $4, W \neq \varnothing$. Furthermore $f_{i}(W)=W$ for $i=$ $1,2, \cdots, n$. Let $H$ be the convex closure of $W$. By normal structure $H$ contains a point $x$ such that

$$
\sup \{\|x-z\|: z \in H\}=r<\delta(H)
$$

provided $\delta(H)>0$. As before, we assume $\delta(H)>0$ and obtain a contradiction. Let

$$
C=\left\{x \in X^{*}:\|x-z\| \leqq r \text { for all } z \in H\right\} .
$$

Then $C$ is a nonempty closed convex subset of $X^{*}$ and, moreover,

$$
C=\left\{x \in X^{*}:\|x-z\| \leqq r \text { for each } z \in W\right\} .
$$

Thus $f_{i}(C) \subseteq C$ and $C=X^{*}$, which is impossible since $\delta(C \cap H) \leqq r<$ $\delta(H)$. Hence $\delta(H)=0$, so $H$ consists of the desired fixed point.

Several questions remain unanswered, the most notable perhaps being:

(1) Is Theorem 2 true with strict convexity deleted?

(2) Is Theorem 3 true with the hypothesis of normal structure deleted?

The answers to these questions are not even known in the case that $\mathfrak{F}$ consists of a single mapping (cf. [4], [7]).

\section{REFERENCES}

1. M. S. Brodskii and D. P. Milman, On the center of a convex set, Dokl. Akad. Nauk SSSR (N. S.) 59 (1948), 837-840.

2. M. M. Day, Fixed-point theorems for compact convex sets, Ill. J. Math. 5 (1961), 585-590.

3. Ralph De Marr, Common fixed-points for commuting contraction mappings, Pac. J. Math 13 (1963), 1139-1141.

4. M. Edelstein, On non-expansive mappings of Banach spaces, Proc. Cambridge Philos. Soc. 60 (1964), 439-447.

5. D. Göhde, Über Fixpunkte bei stetigen Selbstabbildungen mit kompakten Iterierten, Math. Nach. 28 (1964), 45-55.

6. S. Kakutani, Two fixed-point theorems concerning bicompact sets, Proc. Imp. Acad. Tokyo 14 (1938), 242-245.

7. W. A. Kirk, A fixed point theorem for mappings which do not increase distances, Amer. Math. Monthly, 72 (1965), 1004-1006.

8. A. Markov, Quelques thêorêmes sur les ensembles abèliens, Dokl. Akad. Nauk SSSR (N. S.) 10 (1963), 311-314.

Received April 5, 1965.

UNIVERSITY OF CALIFORNIA, RIVERSIDE 



\section{PACIFIC JOURNAL OF MATHEMATICS}

\section{EDITORS}

H. SAMELSON

Stanford University

Stanford, California

R. M. BLUMENTHAL

University of Washington

Seattle, Washington 98105

\section{*J. DugundJI}

University of Southern California Los Angeles, California 90007

RICHARD ARENS

University of California

Los Angeles, California 90024

\section{ASSOCIATE EDITORS}

E. F. BECKENBACH
F. WOLF

K. YosIDA

\section{SUPPORTING INSTITUTIONS}

\author{
UNIVERSITY OF BRITISH COLUMBIA \\ CALIFORNIA INSTITUTE OF TECHNOLOGY \\ UNIVERSITY OF CALIFORNIA \\ MONTANA STATE UNIVERSITY \\ UNIVERSITY OF NEVADA \\ NEW MEXICO STATE UNIVERSITY \\ OREGON STATE UNIVERSITY \\ UNIVERSITY OF OREGON \\ OSAKA UNIVERSITY \\ UNIVERSITY OF SOUTHERN CALIFORNIA
}

\author{
STANFORD UNIVERSITY \\ UNIVERSITY OF TOKYO \\ UNIVERSITY OF UTAH \\ WASHINGTON STATE UNIVERSITY \\ UNIVERSITY OF WASHINGTON \\ AMERICAN MATHEMATICAL SOCIETY \\ CHEVRON RESEARCH CORPORATION \\ TRW SYSTEMS \\ NAVAL ORDNANCE TEST STATION
}

Mathematical papers intended for publication in the Pacific Journal of Mathematics should be typewritten (double spaced). The first paragraph or two must be capable of being used separately as a synopsis of the entire paper. It should not contain references to the bibliography. Manuscripts may be sent to any one of the four editors. All other communications to the editors should be addressed to the managing editor, Richard Arens at the University of California, Los Angeles, California 90024 .

50 reprints per author of each article are furnished free of charge; additional copies may be obtained at cost in multiples of 50 .

The Pacific Journal of Mathematics is published monthly. Effective with Volume 16 the price per volume (3 numbers) is $\$ 8.00$; single issues, $\$ 3.00$. Special price for current issues to individual faculty members of supporting institutions and to individual members of the American Mathematical Society: $\$ 4.00$ per volume; single issues $\$ 1.50$. Back numbers are available.

Subscriptions, orders for back numbers, and changes of address should be sent to Pacific Journal of Mathematics, 103 Highland Boulevard, Berkeley 8, California.

Printed at Kokusai Bunken Insatsusha (International Academic Printing Co., Ltd.), No. 6, 2-chome, Fujimi-cho, Chiyoda-ku, Tokyo, Japan.

PUBLISHED BY PACIFIC JOURNAL OF MATHEMATICS, A NON-PROFIT CORPORATION

The Supporting Institutions listed above contribute to the cost of publication of this Journal, but they are not owners or publishers and have no responsibility for its content or policies.

* Paul A. White, Acting Editor until J. Dugundji returns. 


\section{Pacific Journal of Mathematics}

\section{Vol. 18, No. 2 \\ April, 1966}

Alexander V. Arhangelskii, On closed mappings, bicompact spaces, and a problem of P. Aleksandrov .............................. 201

A. K. Austin, A note on loops . . . . . . . . . . . . . . . . . . . . . . . . . . . . 209

Lawrence Peter Belluce and William A. Kirk, Fixed-point theorems for families of contraction mappings...................... 213

Luther Elic Claborn, Every abelian group is a class group ............ 219

Luther Elic Claborn, A note on the class group .................. 223

Robert Stephen De Zur, Point-determining homomorphisms on multiplicative semi-groups of continuous functions............. 227

Raymond William Freese, A convexity property ................ 237

Frederick Paul Greenleaf, Characterization of group algebras in terms of their translation operators ......................... 243

Andrzej Hulanicki, On the spectral radius of hermitian elements in group algebras....................................... 277

Michael Bahir Maschler and Bezalel Peleg, A characterization, existence proof and dimension bounds for the kernel of a game ............ 289

Yiannis (John) Nicolas Moschovakis, Many-one degrees of the predicates

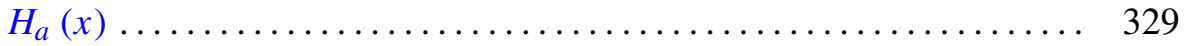

G. O. Okikiolu, $n$th order integral operators associated with Hilbert transforms.

C. E. Rickart, Analytic phenomena in general function algebras ... 361

K. N. Srivastava, On an entire function of an entire function defined by Dirichlet series

Paul Elvis Waltman, Oscillation criteria for third order nonlinear differential equations .......................... 